\title{
EFEITO RESIDUAL DAS APLICAÇÕES DE FONTES DE FÓSFORO EM GRAMÍNEAS FORRAGEIRAS SOBRE O CULTIVO SUCESSIVO DA SOJA EM VASOS $\left({ }^{1}\right)$
}

\author{
SÍLVIO JÚNIO RAMOS $\left({ }^{2 *, 5}\right)$; VALDEMAR FAQUIN $\left({ }^{3,5}\right)$; CARLOS RIBEIRO RODRIGUES $\left({ }^{4}\right)$; \\ CARLOS ALBERTO SILVA $(3,5)$
}

\begin{abstract}
RESUMO
O objetivo deste trabalho foi avaliar em dois solos adubados com fertilizantes fosfatados, o efeito residual das aplicações de fontes de $\mathrm{P}$ em gramíneas forrageiras sobre o cultivo sucessivo da soja em vasos. Para tal, foram realizados dois experimentos, um em Cambissolo e outro em Latossolo, utilizandose vasos com $4 \mathrm{dm}^{3}$ de solo. Para cada solo, o delineamento experimental foi inteiramente casualizado, em esquema fatorial $5 \times 2$, sendo cinco tratamentos de cobertura dos solos, representadas pelo cultivo prévio de quatro gramíneas forrageiras como plantas de cobertura (braquiarão, braquiária, milheto e sorgo forrageiro) mais o solo sem cultivo prévio de gramíneas e duas fontes de P (Superfosfato triplo SFT e Fosfato reativo de arad - FRA), com quatro repetições. As gramíneas forrageiras foram colhidas na fase de pré-florescimento, sendo em seguida cultivada a soja como cultura de sucessão sobre as raízes e palhada. No Cambissolo, quando adubado com a fonte de P de menor solubilidade (FRA), o cultivo prévio das forrageiras proporcionou, na soja cultivada em sucessão, maiores crescimento, produção, acúmulo de $\mathrm{P}$ e aproveitamento do efeito residual do P aplicado. Para o Latossolo, esse efeito não foi observado. Em ambos os solos, sem o cultivo prévio de gramíneas forrageiras, o SFT foi superior que o FRA para todas as variáveis avaliadas. Dentre as gramíneas estudadas, não se observou efeito definido do seu cultivo prévio sobre as variáveis avaliadas na soja cultivada em sucessão.
\end{abstract}

Palavras-chave: aproveitamento de fósforo, cobertura vegetal, sucessão de culturas.

\section{ABSTRATC \\ RESIDUAL EFFECT OF P SOURCES APPLICATION IN FORAGE GRASSES ON THE SUCCESSIVE CULTIVATION OF SOYBEAN}

The present work was carried out to evaluate in two different soils fertilized with different phosphorus sources the use of phosphorus and the soybean yield grown in succession to forage grasses. Two experiments were carried out using Inceptsol (Cambisol) and Oxisol (Latosol), using four $\mathrm{dm}^{3}$ pots with soil. The experimental were carried out in a completely randomized design in a $5 \times 2$ factorial scheme, the five treatments being of soil cover, represented by the previous cultivation of the four forage plants (Brachiaria decumbens, Brachiaria brizantha, Pennisetum glaucum and Sorghum bicolor), plus the soil without cultivation and two sources of P (Triple Superphosphate - TSP and Arad Reactive Phosphate -

( $\left.{ }^{1}\right)$ Recebido para publicação em 24 de junho de 2009 e aceito em 3 de agosto de 2009. Extraído da Dissertação de Mestrado apresentada pelo primeiro autor ao Programa de Pós-Graduação em Ciência do Solo, UFLA, Lavras (MG). Financiado pelo CNPq e pela FAPEMIG.

$\left({ }^{2}\right)$ Doutorando em Ciência do Solo - Departamento de Ciência do Solo - DCS, Universidade Federal de Lavras-UFLA, Lavras (MG), Brasil.. E-mail: silviojramos@gmail.com $\left(^{*}\right)$ Autor correspondente.

$\left(^{3}\right)$ Departamento de Ciência do Solo- UFLA. E-mail: vafaquin@ufla.br; csilva@ufla.br

$\left({ }^{4}\right)$ Universidade Federal Rural de Pernambuco, Garanhuns (PE), Brasil. E-mail: carlos_rrodrigues@yahoo.com.br

$\left({ }^{5}\right)$ Bolsista do CNPq. 


\begin{abstract}
ARP). The cover forage plants were harvested in the flowering, being cultivated following on straw and root, the soybean as succession culture, the soybean was harvested after had completed the development cycle. In Inceptsol, when fertilized with the lower solubility (ARP) P source, the previous cultivation of the forage plants promoted larger growth, production and use of the residual effect of applied $\mathrm{P}$ in the soybean cultivated in succession; the same was not observed in Oxisol. For the soluble source (TSP), the previous cultivation of the forage grasses didn't affect those variables in the soybean cultivated in Inceptsol and, in a general way, in Oxisol, it was harmful, when compared with the treatment without cultivation. Among the forage grasses studied, a defined effect of their previous cultivation on the evaluating variables in the soybean cultivated in succession was not observed.
\end{abstract}

Key words: use of phosphorus, vegetable coverage, crop succession.

\section{INTRODUÇÃO}

O progresso tecnológico tem proporcionado a expansão de novas áreas de cultivo da soja no Brasil (Bertrand e Pasquis, 2004). A importância dessa cultura é singular, pois, há alta participação em produtos exportados, além de ser grande opção de cultivo para os agricultores.

Grande parte da expansão do cultivo da soja ocorre em solos sob vegetação de cerrados, que apresentam condições favoráveis de clima, sem limitação de temperatura e radiação solar, mas, nos quais há problemas no suprimento adequado de nutrientes. Nesses solos, o fornecimento de fósforo (P) via adubação é prática essencial, os quais, apresentam intensa deficiência de $\mathrm{P}$, devido à acidez excessiva à presença de elevadas proporções de óxidos de Fe e Al na fração argila, que aumenta muito a adsorção de fosfatos e a formação de precipitados com $\mathrm{Fe}$ e $\mathrm{Al}$, reduzindo, conseqüentemente, a disponibilidade de $\mathrm{P}$ para as plantas (RAIJ, 1991; Novais e SMYTH, 1999).

Nas condições de clima e solo de cerrado, o emprego do sistema de plantio direto (SPD) ou da integração lavoura-pecuária tem surgido como alternativa para garantir a sustentabilidade da agropecuária. Na integração entre lavouras anuais e pastagens, além de viabilizar o desenvolvimento das duas atividades, pois, promove a rotação de culturas e contribui para a proteção e conservação da água e do solo, é essencial na viabilização da semeadura direta (BROCH et al., 1997). De acordo com LANGE et al. (2004), espécies como milheto, braquiária e sorgo forrageiro têm demonstrado importante papel na integração lavoura-pecuária, aumentando a produção de palhada na região do cerrado.

Segundo Igue(1984), as gramíneas possuem maior volume de raiz, melhorando a porosidade e agregação do solo, além de representar a melhor alternativa na associação com leguminosas comerciais. Assim, Pitol et al. (2001) e KLuthCouskiI e STONE (2003) relatam que em diversas áreas de cerrado, a soja promoveu maior produção sobre a palhada de plantas do gênero Brachiaria, principalmente em sucessão à Brachiaria brizantha. Entretanto, FrANCISCO (2002) e Seguatelli (2004) verificaram que a soja em sucessão a Eleusine coracana (L.) Gaert (capim pé-degalinha), não promoveu ganhos na produção de grãos, no entanto, o capim pé-de-galinha proporcionou maior produção de fitomassa no solo.

A adubação fosfatada em sistema de plantio direto tem sido realizada em superfície, sem a incorporação (CORRÊA et al., 2004), com uso de fontes solúveis como o superfosfato triplo, superfosfato simples e monoamônio fosfato. Recentemente, têm sido avaliadas fontes reativas, como o fosfato de Arad. Esses fosfatos, além de terem custo inferior, revelam no primeiro ano, resultados equivalentes ao do superfosfato triplo (RAJAN et al., 1996; Sousa e LobATO, 2003; Horowitz e Meurer, 2004), tanto em solos com teores iniciais médios de P (CHOUdHARY et al., 1994), quanto naqueles com teores baixos (FотумA et al., 1996). Segundo Novais e SMYTH (1999), os fertilizantes de menor reatividade, ao disponibilizarem mais lentamente o $\mathrm{P}$, minimizam os processos de fixação e podem favorecer a maior eficiência de utilização do nutriente pelas culturas.

Assim, o objetivo do presente trabalho foi avaliar o efeito residual das aplicações de fontes de $\mathrm{P}$ em gramíneas forrageiras sobre $\mathrm{o}$ aproveitamento de $\mathrm{P}$ e o rendimento de grãos da soja cultivada em sucessão.

\section{MATERIAL E MÉTODOS}

Foram realizados dois experimentos em casa de vegetação, em Lavras, (MG), utilizando vasos com $4 \mathrm{dm}^{3}$ de solo, em amostras coletadas na camada de 0-20 cm de um Cambissolo Háplico Tb distrófico típico textura média e Latossolo Vermelho distrófico típico textura muito argilosa. O primeiro solo foi coletado no município de Nazareno (MG) e o segundo em Lavras (MG). Ambos os solos foram coletados sob vegetação natural sem cultivo prévio.

Pelas análises físicas e químicas dos solos, conforme método descrito pela EMBRAPA (1999), e mineralógicas conforme Giarola (1994) para o Cambissolo e Souza (2005) para o Latossolo, antes do 
cultivo das gramíneas forrageiras, constataram-se os seguintes resultados respectivamente, para o Cambissolo e Latossolo: teor de areia: 55 e $21 \mathrm{dag}$ kg1; teor de silte: 16 e $9 \mathrm{dag} \mathrm{kg}^{-1}$; teor de argila: 29 e 70 dag $\mathrm{kg}^{-1} ; \mathrm{pH}$ em água: 5,4 e 4,7; MOS: 2,1 e 4,9 dag $\mathrm{kg}^{-1}$; P: 0,6 e $0,9 \mathrm{mg} \mathrm{dm}^{-3}$; K: 20 e $20 \mathrm{mg} \mathrm{dm}^{-3}$; Ca: 0,7 e $0,6 \mathrm{cmol}_{\mathrm{c}} \mathrm{dm}^{-3} ; \mathrm{Mg}: 0,2$ e $0,2 \mathrm{cmol}_{\mathrm{c}} \mathrm{dm}^{-3} ; \mathrm{Al}: 0,7 \mathrm{e}$ $1,1 \mathrm{cmol}_{\mathrm{c}} \mathrm{dm}^{-3} ; \mathrm{H}+\mathrm{Al}: 2,3$ e $7,0 \mathrm{cmol}_{\mathrm{c}} \mathrm{dm}^{-3} ; \mathrm{P}-\mathrm{rem}: 25,2$ e $10,2 \mathrm{mg} \mathrm{L}^{-1} ; \mathrm{Fe}_{2} \mathrm{O}_{3}: 23,0$ e $171,8 \mathrm{~g} \mathrm{~kg}^{-1} ; \mathrm{Al}_{2} \mathrm{O}_{3}: 155,0$ e $319,1 \mathrm{~g} \mathrm{~kg}^{-1}$.

Em ambos os solos, cultivaram-se previamente gramíneas forrageiras como plantas de cobertura, adubadas com fontes de fósforo de diferentes solubilidades e, posteriormente, nos mesmos vasos, cultivou-se a soja sobre as raízes e palhada das forrageiras. Para cada solo, utilizou-se o delineamento experimental inteiramente casualizado, em esquema fatorial $5 \times 2$, sendo cinco tratamentos de cobertura dos solos, representadas pelo cultivo prévio de quatro forrageiras (Brachiaria decumbens - braquiária, Brachiaria brizantha - braquiarão, Pennisetum glaucum - milheto e Sorghum bicolor - sorgo forrageiro), mais o solo sem cultivo prévio de forrageiras e duas fontes de $\mathrm{P}$ (Superfosfato triplo - SFT, com $46,1 \%$ de $\mathrm{P}_{2} \mathrm{O}_{5}$ total e 46,1\% solúvel em CNA+água; e Fosfato Reativo de Arad - FRA, com $33,1 \%$ de $\mathrm{P}_{2} \mathrm{O}_{5}$ total e $9,4 \%$ solúvel em ácido cítrico), com quatro repetições. Os solos sem cultivo prévio foram representados pelos dois solos adubados com as duas fontes de $\mathrm{P}$, na mesma época dos tratamentos com as forrageiras, mas que não foram cultivados, permanecendo, portanto, em pousio durante o cultivo prévio das forrageiras.

Antes do cultivo das gramíneas, com base na análise química dos solos, foi efetuada a calagem visando elevar a saturação por bases a $50 \%$, utilizando-se calcário dolomítico calcinado e micropulverizado, com $35 \%$ de $\mathrm{CaO}, 14 \%$ de $\mathrm{MgO}$ e PRNT $=100 \%$.

Após incubação dos solos por 25 dias com umidade próxima a $60 \%$ do volume total de poros (VTP), as fontes de fósforo foram incorporadas nas doses de 150 e $250 \mathrm{mg} \mathrm{dm}^{-3}$ de $\mathrm{P}$ para o Cambissolo e Latossolo, respectivamente, com base no $P$ total de cada fonte. Pretendeu-se, para as duas fontes, aplicar doses de $\mathrm{P}$ menores que as adequadas recomendadas por Alvarez V. e Fonseca (2000) para ensaios em vasos. Assim, o Latossolo, sendo mais argiloso e com características mineralógicas mais favoráveis à adsorção específica de $\mathrm{P}$, recebeu dose maior do nutriente. Juntamente com a adubação fosfatada foi efetuada uma adubação com $80 \mathrm{mg}$ de N; $80 \mathrm{mg}$ de K; $60 \mathrm{mg}$ de $\mathrm{S} ; 0,5 \mathrm{mg}$ de B; 1,5 mg de Cu e $5 \mathrm{mg}$ de $\mathrm{Zn}$ por $\mathrm{dm}^{3}$ de solo, na forma de solução nutritiva, utilizando as seguintes fontes: $\mathrm{NH}_{4} \mathrm{NO}_{3}, \mathrm{KNO}_{3}$, $\left(\mathrm{NH}_{4}\right)_{2} \mathrm{SO}_{4}, \mathrm{H}_{3} \mathrm{BO}_{3}, \mathrm{CuSO}_{4} \cdot 5 \mathrm{H}_{2} \mathrm{O}$ e $\mathrm{ZnSO}_{4} \cdot 7 \mathrm{H}_{2} \mathrm{O}$.

Em seguida, foram semeadas 10 sementes por vaso de cada forrageira, e desbastadas para quatro plântulas uma semana após a emergência. Durante o cultivo, as forrageiras receberam adubações nitrogenada e potássica em cobertura, aplicando-se $400 \mathrm{mg} \mathrm{dm}^{-3}$ de cada nutriente para a braquiária e braquiarão e, $500 \mathrm{mg} \mathrm{dm}^{-3}$ de cada nutriente para o sorgo e milheto, parceladas em sete aplicações, utilizando o $\mathrm{NH}_{4} \mathrm{NO}_{3}$ e $\mathrm{KCl}$. A umidade do solo foi mantida a $60 \%$ do VTP, por meio da pesagem dos vasos e adição de água deionizada, inclusive para os vasos do tratamento sem o cultivo das forrageiras.

As forrageiras foram cultivadas até a fase de pré-florescimento, quando a parte aérea foi cortada a $2 \mathrm{~cm}$ da superfície do solo; em seguida, foram secas em estufa a $65-70{ }^{\circ} \mathrm{C}$ até obter-se massa constante e picadas em pedaços de 2 a $5 \mathrm{~cm}$, sendo depositadas na superfície dos solos dos vasos correspondentes, na dose de $16 \mathrm{~g}$ de massa seca por vaso, simulando o sistema de integração lavoura-pecuária, onde parte da palhada permanece no local, de acordo com a metodologia proposta por CORRÊA et al. (2004). Para maiores detalhes sobre a discussão dos dados de produção de matéria seca das gramíneas forrageiras, consultar RAmOs et al. (2009).

Após a deposição da palhada nos vasos, foi efetuada adubação básica na forma de solução nutritiva com $70 \mathrm{mg}$ de $\mathrm{N} ; 50 \mathrm{mg}$ de $\mathrm{K} ; 30 \mathrm{mg}$ de S; $0,5 \mathrm{mg}$ de $\mathrm{B} ; 1,5 \mathrm{mg}$ de $\mathrm{Cu}$ e $5 \mathrm{mg}$ de $\mathrm{Zn}$ por $\mathrm{dm}^{3}$, usando as mesmas fontes citadas para as forrageiras.

Posteriormente, foram semeadas 10 sementes de soja, sendo desbastadas para duas plântulas uma semana após a emergência. Até a fase de florescimento da cultura, foram aplicados em cobertura $230 \mathrm{mg}$ de $\mathrm{N} ; 200 \mathrm{mg}$ de $\mathrm{K} ; 30 \mathrm{mg}$ de $\mathrm{S}$ por $\mathrm{dm}^{3}$, parcelados em cinco aplicações. Durante todo o ciclo da cultura, a umidade do solo foi mantida a $60 \%$ do VTP, por meio da pesagem dos vasos e adição de água deionizada.

A colheita da planta de soja foi feita no fim do ciclo, secando-se o material vegetal em estufa a 65-70 ${ }^{\circ} \mathrm{C}$, para obtenção da matéria seca da parte aérea (folhas + caule) e dos grãos, nas quais foram realizadas análises químicas para o $\mathrm{P}$, de acordo com Malavolta et al. (1997). Multiplicando-se os teores de P com a matéria seca produzida, foi determinado o acúmulo de $\mathrm{P}$ total (parte aérea + grãos) da soja. Uma vez obtidos esses dados, estimaram-se, os seguintes índices: eficiência de utilização $(\mathrm{EU})=\left[(\mathrm{g} \text { matéria seca total })^{2} /(\mathrm{mg}\right.$ de $\mathrm{P}$ total acumulado)] (SIDDQI e Glass, 1981); eficiência de aproveitamento do P aplicado (EAPA) $=[(\mathrm{mg}$ P total acumulado) / (mg de P aplicado em cada solo - mg de $P$ total acumulado nas gramíneas) $x$ 100]. 
Os dados obtidos foram submetidos à análise de variância e aos testes de média com o auxílio do programa estatístico SISVAR ${ }^{\circledR}$ (FERREIRA, 2000). As médias dos tratamentos componentes do fatorial foram comparadas entre si pelo teste de Scott $\operatorname{Knott}(P=0,05)$.

\section{RESULTADOS E DISCUSSÃO}

Verificou-se interação significativa entre as fontes de $\mathrm{P}$ e o cultivo prévio das gramíneas em relação às variáveis avaliadas na soja (Figuras $1 \mathrm{e}$ 2). Observa-se na figura $1 \mathrm{a}$ e $\mathrm{b}$, para a fonte de $\mathrm{P}$ solúvel (SFT), que o tratamento sem cultivo prévio das forrageiras promoveu maior produção de matéria seca da parte aérea (MSPA) da soja que os demais tratamentos. Com esse resultado mostra que, em ambos os solos, o cultivo prévio das gramíneas de cobertura diminuiu o efeito residual da fonte de P solúvel (SFT) para o cultivo da soja em sucessão.
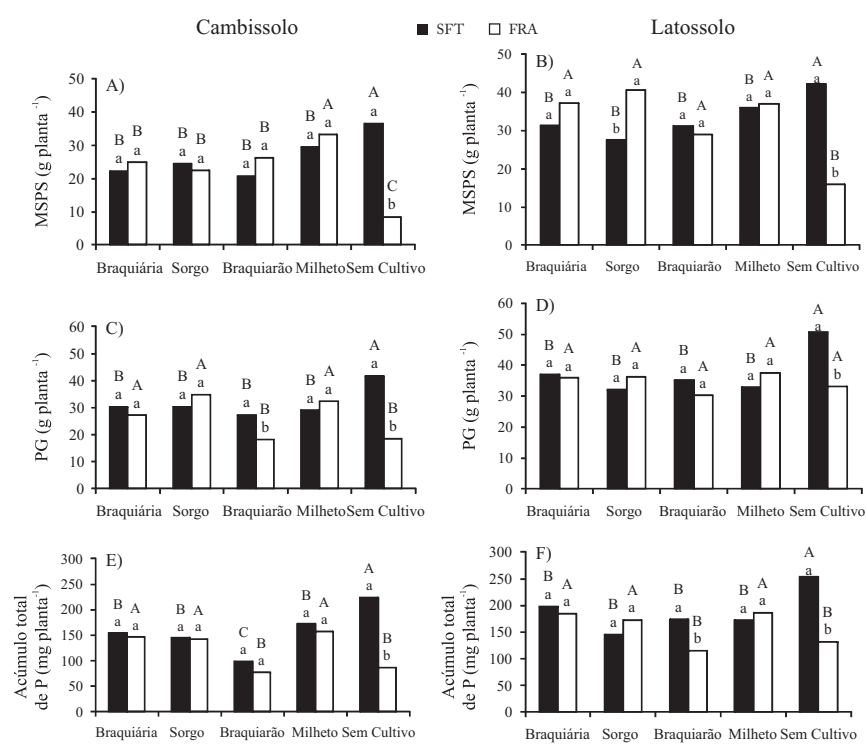

Figura 1. Matéria seca da parte aérea (MSPA) (A e B), produção de grãos (PG) (C e D) e acúmulo de $\mathrm{P}$ total (E e F) da soja cultivada em sucessão a gramíneas de cobertura e em solo sem cultivo, adubadas com Super Fosfato Triplo (SFT) e Fosfato Reativo de Arad (FRA) no Cambissolo e Latossolo. Em cada solo, médias seguidas de mesma letra, minúscula, comparando as fontes de P para cada gramínea forrageira e solo sem cultivo, e maiúscula, comparando as gramíneas forrageiras e solo sem cultivo em cada fonte de $\mathrm{P}$, não diferem entre si (Scott Knott 5\%).

Entre as gramíneas, não houve, de maneira geral, diferença entre elas em relação à MSPA e PG da soja, porém, aumentaram essa produção quando comparadas às obtidas sem o cultivo prévio das gramíneas forrageiras e com a aplicação de fertilizante fosfatado de menor solubilidade (FRA), demonstrando o efeito positivo do uso de plantas de cobertura. $\mathrm{O}$ comportamento semelhante entre as fontes de $\mathrm{P}$ utilizadas, nos tratamentos com cultivo prévio de gramíneas, pode ser atribuído, possivelmente, à produção de ácidos orgânicos no solo pelas gramíneas, os quais contribuíram para maior solubilização do fertilizante menos solúvel. NovaIs e Smyth (1999) e Pavinato e Rosolem (2008) destacam que a decomposição da matéria orgânica produz ácidos que podem agir na disponibilidade de $\mathrm{P}$ no solo. Este fato fica evidente no maior acúmulo de $\mathrm{P}$ total observado na soja cultivada em sucessão às gramíneas, em comparação ao solo sem cultivo prévio, adubado com FRA, à exceção do braquiarão em ambos os solos (Figura $1 \mathrm{e}, \mathrm{f}$ ).

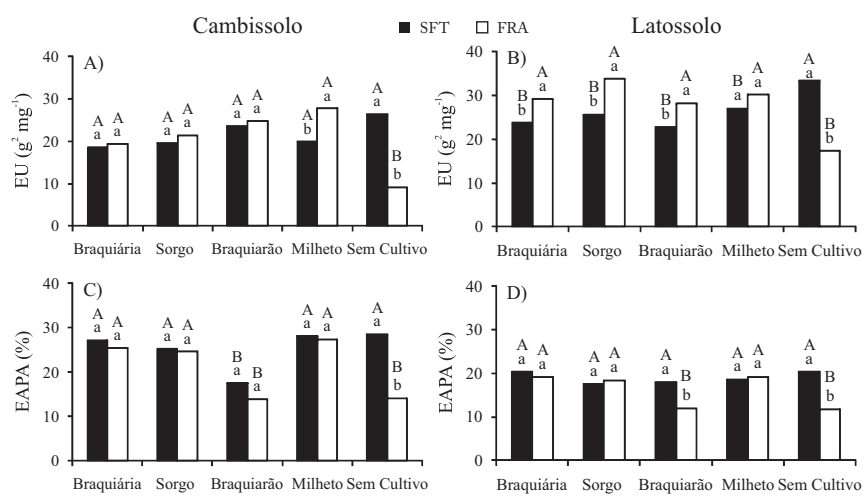

Figura 2. Eficiência de utilização (EU) (A e B) e eficiência de aproveitamento do P aplicado (EAPA) (C e D) da soja cultivada em sucessão a gramíneas de cobertura e em solo sem cultivo, adubadas com Super Fosfato Triplo (SFT) e Fosfato Reativo de Arad (FRA) no Cambissolo e Latossolo. Em cada solo, médias seguidas de mesma letra, minúscula, comparando as fontes de $\mathrm{P}$ para cada gramínea forrageira e solo sem cultivo, e maiúscula, comparando as gramíneas forrageiras e solo sem cultivo em cada fonte de $\mathrm{P}$, não diferem entre si (Scott Knott 5\%).

Na produção de grãos da soja (Figura $1 \mathrm{c}, \mathrm{d}$ ), o desenvolvimento foi semelhante à MSPA, na qual se observa que o tratamento sem o cultivo prévio das forrageiras promoveu maior produção de grãos da soja apenas com o SFT, em ambos os solos. Dentro da mesma fonte, para ambos os solos, as forrageiras não influenciaram a PG da soja, à exceção do braquiarão no Cambissolo adubado com FRA, que promoveu menor produção que as demais gramíneas (Figura 1 c). TORRES (2003) não constatou diferença significativa na produção de grãos da soja quando cultivada em sucessão a oito tratamentos de cobertura do solo. Da mesma forma, Francisco (2002) e SEgUATELLI (2004), observaram que o cultivo da soja em sucessão a Eleusine coracana não alterou a produção de grãos na soja. 
Dentro da mesma forrageira, apenas para a soja em sucessão ao braquiarão no Cambissolo (Figura 1c), as fontes de P diferiram entre si, sendo a maior PG da soja obtida com o SFT. Peruzzo e Wiethölter (1999), utilizando fosfatos naturais reativos, verificaram rendimento nos grãos da soja semelhante ao obtido com superfosfato triplo, no primeiro cultivoem solo com teor médio de $\mathrm{P}$.

$\mathrm{O}$ acúmulo de $\mathrm{P}$ pela planta é função de seus teores nos tecidos e, principalmente, da produção de matéria seca. Assim, com o acúmulo de $\mathrm{P}$ total pela soja (Figura 1 e,f) o comportamento foi semelhante ao da MSPA e PG, em função dos tratamentos de fontes de $\mathrm{P}$ e cultivo ou não de forrageiras de cobertura, em ambos os solos. Verificou-se que no Latossolo, em razão da maior CTC, que atua com dreno de $\mathrm{Ca}$, houve tendência de maior acúmulo de $\mathrm{P}$ na planta comparado ao Cambissolo (Figuras 1 e,f). Esse fato fica evidente, principalmente no tratamento com FRA sem cultivo prévio de gramíneas, onde, o acúmulo de $\mathrm{P}$ na soja foi mais elevado que no Cambissolo. A influência de drenos na dissolução de fosfatos naturais e o aumento da disponibilidade de P no solo têm sido bastante destacados por Novais e SMYTH (1999) e Horowitz e Meurer (2004). Segundo Chien e Meron (1995) e Novais e Sмүтн (1999), a existência de componentes do solo, ou plantas, atuando como drenos de $\mathrm{P}$ e, principalmente de $\mathrm{Ca}$, é tida como fator preponderante para a dissolução e efetividade dos fosfatos naturais reativos.

Pode-se afirmar que, somente para os tratamentos sem cultivo de gramíneas, com SFT, de forma consistente, os resultados foram superiores ao FRA (Figura 1). Esse fato mostra a importância de se formar palhada com gramíneas para o aumento da eficiência de fosfatos naturais no cultivo da soja em sucessão a outras culturas. Convém destacar que, KORNDÖRFER et al. (1999), trabalhando com fosfatos naturais farelados de Arad, Marrocos e Gafsa, obtiveram resultados similares aos do superfosfato triplo granulado no cultivo do milho em solos de cerrado. Por outro lado, Richart et al. (2006), antecipando a adubação fosfatada na cultura do milheto, em Latossolo Vermelho eutroférrico, verificaram superioridade do superfosfato triplo em relação ao fosfato natural reativo na produção de matéria seca total da soja cultivada em sucessão. No entanto, para a produção de grãos da soja, esses mesmos autores não observaram diferença significativa entre as fontes, mostrando que os fosfatos se equivaleram no fornecimento de $\mathrm{P}$ para a cultura. Esses resultados corroboram com diversos trabalhos que indicam ser os fosfatos naturais reativos bastante efetivos em suprir $P$ às culturas, uma vez que se constituem em fonte de liberação controlada de $\mathrm{P}$ (Horowitz e Meurer, 2004; Sousa e Lobato, 2003).

Para evitar a seleção de plantas eficientes na utilização de nutrientes, porém com baixa produção, SidDQI e Glass (1981) propuseram o cálculo da eficiência de utilização em função da concentração do nutriente na matéria seca e não pela unidade acumulada. A figura $2 \mathrm{a}, \mathrm{b}$ revela que, em ambos os solos, quando adubados com o FRA, o cultivo prévio de todas as gramíneas promove maior EU do P dessa fonte em relação ao tratamento sem cultivo; fato não observado quando a fonte de P foi o SFT. Este comportamento assemelha-se ao observado em ambos os solos para a MSPA, PG e acúmulo total de P (Figura 1), mostrando estreita relação entre a EU do P por esse método e o crescimento da soja. A exceção do tratamento sem o cultivo prévio de forrageiras, o FRA foi semelhante ou superior ao SFT na EU de P da soja cultivada em sucessão. De acordo com NovaIs e Sмүтн (1999), os fertilizantes naturais reativos, ao disponibilizarem mais lentamente o $\mathrm{P}$, minimizam os processos de fixação e podem favorecer maior eficiência de utilização do nutriente pelas culturas.

A eficiência de aproveitamento do $\mathrm{P}$ aplicado (EAPA) (Figura $2 \mathrm{c}$,d) representa o percentual do $\mathrm{P}$ aplicado aos solos pelas fontes que não foi absorvido pelas gramíneas, mas foi pela soja, ou seja, o aproveitamento do $P$ residual pela cultura sucessora; da mesma forma para o tratamento sem cultivo. Para ambos os solos, não houve diferença da EAPA pela soja entre os tratamentos quando a fonte de P usada foi o SFT, à exceção, no Cambissolo, para a soja em sucessão ao braquiarão (Figura 2 c).

Para a fonte menos solúvel (FRA), de maneira geral, o cultivo prévio das gramíneas promoveu maior aproveitamento pela soja do $\mathrm{P}$ residual dessa fonte (EAPA), quando comparado com o tratamento sem cultivo, sendo esse efeito mais acentuado no Cambissolo (Figura 2 c). Com esses resultados, constata-se que o cultivo prévio das gramíneas de cobertura proporcionou melhor aproveitamento do efeito residual do $P$ pela cultura subsequente, quando a fonte usada foi de menor solubilidade (FRA), principalmente no solo mais arenoso com menores teores de óxidos de Fe e Al.

Vale ressaltar o possível efeito positivo de ácidos liberados no solo pela palhada das gramíneas, os quais, possivelmente, contribuíram para maior dissolução do FRA e disponibilidade de P para absorção pela soja, conforme já comentado.

De maneira geral, independentemente da fonte 
de $\mathrm{P}$, a EAPA pela soja alcançou valores próximos de $30 \%$ no Cambissolo e de $20 \%$ no Latossolo. Assim, o Cambissolo com baixo teor de argila e elevado valor de P-rem, foi o que proporcionou na soja em sucessão o maior aproveitamento de $\mathrm{P}$ aplicado (Figura $2 \mathrm{c}$ ). Resultados semelhantes foram observados por Novelino (1999) e Bonfim et al. (2003), que obtiveram menor aproveitamento de $\mathrm{P}$ com o aumento do poder tampão de fosfato dos solos. De acordo com NovaIs e Sмүтн (1999), os solos das regiões tropicais, geralmente ácidos e com predominância de argilas sexquioxídicas, atuam como forte dreno do $\mathrm{P}$ aplicado com os fertilizantes e reduzem drasticamente a disponibilidade e o aproveitamento pelas plantas. Assim, a facilidade de absorção do $\mathrm{P}$ da solução do solo pelas plantas, que está em equilíbrio com a forma lábil, é negativamente relacionada com a energia de ligação de $\mathrm{P}$ e com a capacidade tampão deste elemento no solo. Desse modo, no solo com maior capacidade tampão, houve menor taxa de recuperação do $\mathrm{P}$ aplicado.

Nesse contexto, o atendimento da demanda da cultura, com um mínimo de fixação de $\mathrm{P}$ no solo, constituiu-se em um aspecto importante para a otimização da fertilização fosfatada, aliado às práticas mais efetivas e eficientes de conservação do solo, o que pode reduzir a preocupação da sua degradação e melhorar o aproveitamento de fósforo dos fertilizantes aplicados.

\section{CONCLUSÕES}

1. No Cambissolo, quando adubado com a fonte de P de menor solubilidade (FRA), o cultivo prévio das forrageiras proporcionou na soja cultivada em sucessão maiores crescimento, produção, acúmulo de $\mathrm{P}$ e aproveitamento do efeito residual do P aplicado. Para o Latossolo, esse efeito não foi observado.

2. Em ambos os solos, sem o cultivo prévio de gramíneas forrageiras, o SFT foi superior ao FRA para todas as variáveis avaliadas.

3. Dentre as gramíneas estudadas, não se observou efeito definido do seu cultivo prévio sobre as variáveis avaliadas na soja cultivada em sucessão.

\section{REFERÊNCIAS}

ALVAREZ V., V. H.; FONSECA, D. M. Determinação e uso do fósforo remanescente. Viçosa: Sociedade Brasileira de Ciência do Solo, 2000. v.25, p.27-33. (Boletim Informativo).
BERTRAND, J. P.; PASQUIS, R. L'analyse des déterminants de l'avancée du front du soja en Amazonie brésilienne: le cas du Mato Grosso: rapport final. Paris: Institut National de la Recherche Agronomique (Inra), 2004. 237 p.

BONFIM, E. M. S.; FREIRE, F. J.; SANTOS, M. V. F.; SILVA, T. J. A.; FREIRE, M. B. G. S. Avaliação de extratores para determinação de fósforo disponível de solos cultivados com Brachiaria brizantha. Acta Scientiarum Agronomy, v.25, p.323328, 2003.

BROCH, D. L.; PITOL, C.; BORGES, E. P. Integração agriculturapecuária: plantio direto da soja sobre pastagem na integração agropecuária. Maracaju: Fundação MS, 1997. 24p. (Fundação MS. Informativo Técnico, 01/97).

CHIEN, S. H.; MENON, R. G. Factors affecting the agronomic effectiveness of phosphate rock for direct application. Fertilizer Research, v. 41, p. 277-234, 1995.

CHOUDHARY, M.; PECK, T. R.; PAUL, L. E.; BAILEY, L. D. Longterm comparison of rock phosphate with superphosphate on crop yield in two cereal-legume rotations. Canadian Journal of Plant Science, v. 74, p. 303-310, 1994.

CORRÊA, J. C.; MAUAD, M.; ROSOLEM, C. A. Fósforo no solo e desenvolvimento de soja influenciados pela adubação fosfatada e cobertura vegetal. Pesquisa Agropecuária Brasileira, v.39, p.1231-1237, 2004.

EMPRESA BRASILEIRA DE PESQUISA AGROPECUÁRIA. Embrapa Solos, Embrapa Informática Agropecuária. Manual de análises químicas de solos, plantas e fertilizantes. Brasília: Embrapa Comunicação para Transferência de Tecnologia, 1999. 370p.

FERREIRA, D. F. Análise estatística por meio do SISVAR (Sistema para Análise de Variância) para Windows versão 4.0. In: REUNIÃO ANUAL DA REGIÃO BRASILEIRA DA SOCIEDADE INTERNACIONAL DE BIOMETRIA, 45, 2000, São Carlos. Anais... São Carlos, SP: UFSCar, 2000. p. 255-258.

FRANCISCO, E. A. B. Antecipação da adubação da soja na cultura de Eleusine coracana (L.) Gaertn em sistema de plantio direto. 2002. 58 p. Dissertação (Mestrado em Agronomia) Escola Superior de Agricultura "Luiz de Queiroz"-USP, Piracicaba.

FOTYMA, M.; HAMMOND, L.; KESIK, K. Suitability of North Carolina natural phosphate to Polish agriculture. Fertilizer Research, v.43, p.83-86, 1996.

GIAROLA, N. F. B. Levantamento pedológico, perdas de solo e aptidão agrícola das terras na região sob influência do reservatório de Itutinga/Camargos (MG). 1994. 226 p. Dissertação (Mestrado em Agronomia) - Escola Superior Agricultura de Lavras, Lavras, 1994.

HOROWITZ, N.; MEURER, E. J. Eficiência agronômica dos fosfatos naturais. In: YAMADA, T.; ABDALLA, S. R. S. Fósforo na agricultura brasileira. Piracicaba: Potafos, 2004. p.665-688. 
IGUE, K. Dinâmica da matéria orgânica e seus efeitos na propriedade do solo. Adubação verde no Brasil. Campinas: Fundação Cargill, 1984. p. 232-267.

KLUTHCOUSKI, J.; STONE, L. F. Desempenho de culturas anuais sobre palhada de braquiária. In: KLUTHCOUSKI, J.; STONE, L. F.; AIDAR, H. Integração lavoura-pecuária. Santo Antônio de Goiás: Embrapa Arroz e Feijão, 2003. p. 499-522.

KORNDÖRFER, G.H.; CABEZAS, W.A.L.;HORO, N. Eficiência agronômica de fosfatos naturais reativos na cultura do milho. Scientia Agrícola, v.52, p.391-396, 1999.

LANGE, A.; CABEZAS, W. A. R. L.; TRIVELIN, P. C. O. Matéria seca e ciclagem de nutrientes na palha em solo arenoso em sistema semeadura direta no cerrado. In: FERTBIO, 2004, Lages. Resumos... Lages-SC: UDESC, 2004. CD-ROM.

MALAVOLTA, E.; VITTI, G. C.; OLIVEIRA, S. A. de. Avaliação do estado nutricional das plantas: princípios e aplicações. 2.ed. Piracicaba: POTAFOS, 1997.319p.

NOVAIS, R. F.; SMYTH, T. J. Fósforo em solo e planta em condições tropicais. Viçosa, MG:UFV, 1999. 399p.

NOVELINO, J. O. Disponibilidade de fósforo ao longo do tempo em solos altamente intemperizados avaliadas por extratores químicos e crescimento vegetal. 1999. 70 p. Tese (Doutorado em Agronomia) - Universidade Federal de Viçosa, Viçosa.

PAVINATO, P.S.; ROSOLEM, C.A. Disponibilidade de nutrientes no solo: decomposição e liberação de compostos orgânicos de resíduos vegetais. Revista Brasileira de Ciência do Solo, v.32, p.911-920, 2008.

PERUZZO, G.; WIETHÖLTER, S. Fosfatos naturais reativos: resultados obtidos no Sul do Brasil. In: CONGRESSO BRASILEIRO DE CIÊNCIA DO SOLO, 27., 1999, Brasília. Anais... Brasília: SBCS, 1999. CD-ROM.

PITOL, C.; GOMES, E. L.; ERGES, E. I. Avaliação de cultivares de soja em plantio direto sobre brachiária. In: FUNDAÇÃO MS. Resultados de pesquisa e experimentação: safra 2000/ 2001. Maracaju, 2001. p.40-48.

RAIJ, B. van. Fertilidade do solo e adubação. Piracicaba, Ceres, 1991, 343p.

RAJAN, S. S. S.; WATKINSON, J. H.; SINCLAIR, A. G. Phosphate rocks for direct applications to soils. Advances in Agronomy, v.57, p.77-159, 1996.

RAMOS, S.J.; FAQUIN, V.; RODRIGUES, C.R.; SILVA, C.A.; BOLDRIN, P.F. Biomass production and phosphorus use of forage grasses fertilized with two phosphorus sources. Revista Brasileira de Ciência do Solo, v.33, p.335-343, 2009.

RICHART, A.; LANA, M. C.; SCHULZ, L. R.; BERTONI, J. C.; BRACCINI, A. L. Disponibilidade de fósforo e enxofre para a cultura da soja na presença de fosfato natural reativo, superfosfato triplo e enxofre elementar. Revista Brasileira de Ciência do Solo, v. 30, p.695-705, 2006.
SEGUATELLI, C. R. Produtividade da soja em semeadura direta com antecipação da adubação fosfatada e potássica na cultura de Eleusine coracana (L.) Gaertn. ESALQ, 2004. 58p. Dissertação (Mestrado em Agronomia) - Escola Superior de Agricultura "Luiz de Queiroz"-USP, Piracicaba.

SIDDIQI, M.Y.; GLASS, A. D. M. Utilization index: a modified approach to the estimation and comparison of nutrient utilization efficiency in plants. Journal of Plant Nutrition, v.4, p.289-302, 1981.

SOUSA, D. M. G.; LOBATO, E. Adubação fosfatada em solos da região do Cerrado. Piracicaba, n. 102, 2003. 16p. (Informações Agronômicas. Encarte Técnico)

SOUZA, R. F. de. Dinâmica de fósforo em solos sob influência da calagem e adubação orgânica, cultivados com feijoeiro. 2005. 141p. Tese (Doutorado em Agronomia) - Universidade Federal de Lavras, Lavras, 2005.

TORRES, J. L. R. Estudo das plantas de cobertura na rotação milho-soja em sistema de plantio direto no cerrado, na região de Uberaba-MG. 2003. 108p. Tese (Doutorado em Agronomia). Faculdade de Ciências Agrárias e Veterinárias - UNESP. Jaboticabal. 